\title{
Effects of Adding Intrathecal Fentanyl as Adjunct to Hyperbaric Bupivacaine in Vaginal Hysterectomy: A Double Blinded Randomized Controlled Trial
}

\author{
Dhakal Y
}

\begin{abstract}
Introduction: Spinal anesthesia is the preferred means for gynecological surgeries. Adjuvants to local anesthesia for spinal anesthesia may enhance quality and duration of analgesia. Our study aimed to evaluate efficacy and safety of fentanyl added to bupivacaine for spinal anesthesia. Methods: A prospective, randomized, double blind study was conducted on 60 ASA I or II adult female patients undergoing vaginal hysterectomy under spinal anesthesia. Patients were randomly divided into two groups. Patients in Group B $(n=30)$ were administered $3 \mathrm{~mL}$ of $0.5 \%$ hyperbaric bupivacaine with $0.4 \mathrm{ml} \mathrm{NS}$ and Group $\mathrm{F}(n=30)$ were given $3 \mathrm{~mL}$ of $0.5 \%$ hyperbaric bupivacaine with $0.4 \mathrm{ml}(20 \mu \mathrm{g})$ fentanyl intrathecally. Hemodynamic variables (i.e. heart rate, noninvasive blood pressure, oxygen saturation), onset of motor and sensory block, duration of sensory and motor blockade and any side effects observed were recorded intraoperatively and postoperatively. Results: The duration of sensory and motor blockade was significantly prolonged $(P<0.05)$ in fentanyl group $(268.6 \pm 55.4$ and $182.8 \pm 43.87)$ compared to control group $(235.03 \pm 51.97$ and $149.47 \pm 38.75)$. Similarly, the onset of sensory and motor block was significantly earlier $(P<0.05)$ in group $F(5.2 \pm 2.55$ and $7.8 \pm 2.91)$ compared to group B $(6.63 \pm 2.88$ and $9.97 \pm 3.28)$. There was no significant statistical difference in the incidence of side effects and changes in hemodynamic variables in both the groups. No adverse events were observed during study. Conclusion: Addition of fentanyl to hyperbaric bupivacaine for spinal anesthesia offers early onset, better surgical analgesia, prolongs the duration of analgesia without any significant adverse effects.
\end{abstract}

Key words: Adjuvants, bupivacaine, fentanyl, spinal anesthesia.

\section{INTRODUCTION}

Spinal anesthesia is the preferred means for gynecological surgeries, being simple to perform, economical, produces rapid onset of anesthesia and complete muscle relaxation. Hyperbaric bupivacaine is an amide type of local anesthetic, has high potency, slow onset (5-8 minutes) and long duration of action which is commonly used drug for spinal anesthesia ${ }^{1}$. Intrathecal bupivacaine has good sensory block intraoperatively however, postoperative pain control is a major problem because spinal anesthesia using only local anesthetics is associated with relatively short duration of action, and thus early analgesic intervention is needed in the postoperative period.

Acute post-operative pain is a complex physiological reaction to tissue injury which may result in unpleasant, unwanted sensory and emotional experiences ${ }^{2}$. It can result in delayed healing, delayed mobilization and increased risk of myocardial infarction or ischemia, risk of tachycardia and dysrhythmia. Other published reports indicate that post-operative pain can lead to thromboembolic events, peripheral vasoconstriction, and metabolic acidosis ${ }^{3}$.

\section{Address for correspondence:}

Dr. Yogesh Dhakal

Department of Anaesthesia

Nepalgunj Medical College Teaching Hospital

Kohalpur, Banke, Nepal

Email: drdhakalyogesh@gmail.com
Several agents have been administered epidurally and intrathecally with local anaesthetic; such as opioids, benzodiazepines, neostigmine, clonidine, non-steroidal antiinflammatory agents, vasoconstrictors. The objective of adding such agents is to provide more adequate analgesia, reduce the use of oral analgesics with unwanted side effects, and to prolong the duration of intraoperative and postoperative analgesia. The role of opioid in controlling post-operative pain has developed from understanding for the role of spinal cord for modulating and processing nociceptive stimuli, and discovery of opioid receptors in spinal cord ${ }^{4}$.

Despite with various advantages intrathecal opioids are also associated with numerous complications including respiratory depression, urinary retention, pruritus, nausea and vomiting. Fentanyl is lipophilic opioid, has rapid onset of action and it does not tend to migrate to the fourth ventricle in sufficient concentration when administered intrathecally leading to decreased risk of delayed respiratory depression ${ }^{5}$. Hence, the purpose of this study was to evaluate the effects of intrathecally administered fentanyl $(20 \mathrm{mcg})$ on the onset and duration of hyperbaric bupivacaine induced sensory and motor block, quality of intraoperative and postoperative analgesia and side effects associated with its intrathecal use.

\section{MATERIALS AND METHODS}

The study was carried out in department of Anesthesiology, Nepalgunj Medical College Teaching hospital, Kohalpur. The duration of study was of one year from March 2016 to March 
2017. After approval by the ethical committee, written consent was obtained from all patients preoperatively. Sixty patients (ASA I and II) aged 18 to 65 years scheduled for vaginal hysterectomy under spinal anesthesia were included in this prospective randomized, double blinded study. Patients with contraindication to spinal anesthesia or patients with allergy to the study drugs were excluded from the study. Patients received no premedication, and upon arrival of patients into the operating room, ECG, pulse oximetry, and non-invasive blood pressure were monitored. Following infusion of $500 \mathrm{~mL}$ Lactated Ringers solution and while the patient in the sitting position lumber puncture was performed at L3-L4 level through a midline approach using a 25-gauge Quincke spinal needle ( $B$ Braun medical, Germany). Using a computer generated random numbers, patients were allocated into two groups: group $\mathrm{F}$ received hyperbaric bupivacaine $15 \mathrm{mg}$ and $20 \mu \mathrm{g}$ fentanyl into total of $3.4 \mathrm{~mL}$ volume. Group B received $15 \mathrm{mg}$ hyperbaric bupivacaine and $0.4 \mathrm{ml} \mathrm{NS}$ into total of $3.4 \mathrm{~mL}$ volume.

After intrathecal injection, patients were positioned in lithotomy position. The doctor anesthetist performing the block was blinded to the study drug and recorded the intraoperative data. Vital signs were recorded at 5 min interval intraoperatively until the end of surgery. In the Post Anesthesia Care Unit (PACU), vital signs were recorded every $15 \mathrm{~min}$. The sensory block level was assessed by cold alcohol swap along the midclavicular line bilaterally. The motor block was assessed according to the modified Bromage scale: Bromage 0, the patient is able to move the hip, knee and ankle; Bromage 1, the patient is unable to move the hip but is able to move the knee and ankle; Bromage 2, the patient is unable to move the hip and knee but able to move the ankle; Bromage 3 , the patient is unable to move the hip, knee and ankle. Sensory and motor block was assessed every 2 min for first 20 mins and then every $15 \mathrm{~min}$ intra and post-operatively.

The times to reach T10 dermatome sensory block (onset of sensory block), peak sensory level and Bromage 3 motor block (onset of motor block) were recorded before surgery. All durations were calculated considering the time of spinal injection as time zero. Duration of effective analgesia was defined as the time when patient first complained of pain. Duration was motor block was defined as the time when Bromage 0 was observed. Intraoperatively and postoperatively nausea, vomiting, pruritus and respiratory depression were recorded. Hypotension was defined as a decrease in systolic blood pressure $>30 \%$ of the baseline value or systolic blood pressure < $90 \mathrm{~mm} \mathrm{Hg}$, hypotension was treated with intravenous blouses of $6 \mathrm{mg}$ mephentermine and crystalloid fluids. Bradycardia was defined as a pulse rate of $<50$ beat $/ \mathrm{min}$ and was treated with boluses of $0.5 \mathrm{mg}$ atropine.

\begin{tabular}{|l|c|c|c|}
\hline Parameter & Group B & Group F & p - value \\
\hline Age $(y r s)$ & $48.83 \pm 9.09$ & $47.77 \pm 7.48$ & 0.622 \\
\hline Weight $(\mathrm{Kg})$ & $52.47 \pm 6.15$ & $54.43 \pm 6.91$ & 0.249 \\
\hline Height $(\mathrm{cm})$ & $153.83 \pm 5.75$ & $156.5 \pm 6.55$ & 0.099 \\
\hline BMI & $22.12 \pm 1.7$ & $22.13 \pm 1.59$ & 0.967 \\
\hline
\end{tabular}

Values are in Mean $\pm S D$.

Table I: Demographic parameters.

\begin{tabular}{|l|c|c|c|}
\hline Parameter & Group F & Group B & p - value \\
\hline Onset of sensory block (min) & $5.2 \pm 2.55$ & $6.63 \pm 2.88$ & 0.046 \\
\hline Onset of motor block (min) & $7.8 \pm 2.91$ & $9.97 \pm 3.28$ & 0.009 \\
\hline Duration of sensory block (min) & $268.6 \pm 55.4$ & $182.8 \pm 43.87$ & 0.00 \\
\hline Duration of motor block (min) & $235.03 \pm 51.97$ & $149.47 \pm 38.75$ & 0.00 \\
\hline
\end{tabular}

Values are in Mean $\pm S D$.

Table II: Onset of motor and sensory block and duration of motor and sensory block

\begin{tabular}{|l|c|c|c|}
\hline Parameter & Group F & Group B & p - value \\
\hline Maximum block height & T3-7 & T3-7 & 0.5 \\
\hline Nausea / vomiting & $2 / 30$ & $3 / 30$ & 0.119 \\
\hline Pruritus & $3 / 30$ & $0 / 30$ & \\
\hline
\end{tabular}

Table III: Maximum block height, nausea/ vomiting and pruritus 


\section{RESULTS}

Sixty ASA I and II female patients aged between 18 to 65 years posted for vaginal hysterectomy under spinal anesthesia were selected for the study. The study was undertaken to evaluate the efficacy of fentanyl $(20 \mu \mathrm{g})$ as adjuvant to hyperbaric bupivacaine $(0.5 \%)$ in comparison with hyperbaric bupivacaine $(0.5 \%)$ with NS $(0.4 \mathrm{ml}$.) for spinal anesthesia. The demographic parameters were comparable between the groups (Table I).

The onset of sensory block (T10 level) was earlier in group $\mathrm{F}$ $(5.2 \pm 2.55 \mathrm{~min})$ compared to group B $(6.63 \pm 2.88 \mathrm{~min})$ and it was statistically significant. Similarly, onset of motor block was also earlier in group $F(7.8 \pm 2.91 \mathrm{~min})$ compared to group $B$ $(9.97 \pm 3.28 \mathrm{~min})$ and it was statistically significant (Table II).

The duration of effective analgesia was $268.6 \pm 55.4 \mathrm{~min}$ in group $\mathrm{F}$ compared to $182.8 \pm 43.87$ in group $\mathrm{B}$. The result was statistically significant $(p<0.05)$. At the same time duration of motor block was longer in group $F(235.03 \pm 51.97 \mathrm{~min})$ compared to group B $(149.47 \pm 38.75)$ and it was statistically significant (Table II).

Maximum block height in both the group ranges from T3-7. Nausea/ vomiting occurred in two patients in group $F$ and three patients in group B and the difference was not statistically significant. Pruritus was observed in three patients in group $\mathrm{F}$ and none of the patient in group B (Table III).

Heart rate, systolic blood pressure, diastolic blood pressure, mean arterial pressure and oxygen saturations were comparable between groups and did not change significantly in the intraoperative or postoperative period. No adverse events were encountered in either group of patients.

\section{DISCUSSION}

Gynecological surgeries are preferred under spinal anesthesia as it is simple, easy to perform, economical with rapid onset of anesthesia and complete muscle relaxation. Bupivacaine is long acting amide local anesthetic agent most commonly used for spinal anesthesia. However, the limitation lies on fixed duration of those local anesthetic. So various adjuvant such as opioids, benzodiazepines, neostigmine, clonidine, nonsteroidal anti- inflammatory agents, vasoconstrictors are added to prolong duration of anesthesia and analgesia. The discovery of opioid receptors and subsequent development of the technique of epidural and intrathecal opioid administration is undoubtedly one of the most significant advances in pain management of last four decades. Plethora of studies has shown that spinal opioids can provide profound analgesia with fewer central and systemic adverse effects than the opioids administered systemically. In the same line we tried to evaluate the effects of intrathecally administered fentanyl (20mcg) on the onset and duration of hyperbaric bupivacaine induced sensory and motor block, quality of intraoperative and postoperative analgesia and side effects associated with its intrathecal use.

In my study, included female patients posted for vaginal hysterectomy under spinal anesthesia with 30 patients in each group. The demographic parameters i.e. age, height, weight and BMI were comparable between the groups. The onset of both sensory and motor block was earlier in group $\mathrm{F}(5.2 \pm 2.55$; $7.8 \pm 2.91 \mathrm{~min})$ compared to group $B(6.63 \pm 2.88 ; 9.97 \pm 3.28 \mathrm{~min})$ and the result was statistically significant. The finding was similar to study done by Safdari $\mathrm{H}$ et $\mathrm{al}^{6}$. Similarly, in studies done by Bogra J et al., ${ }^{1}$ Mahendru VN et al., ${ }^{7}$ Biswas BN et al. ${ }^{8}$ and Shende $D$ et al., ${ }^{9}$ the onset of sensory and motor block was earlier in fentanyl group but the results were not statistically significant. The earlier onset with fentanyl can be attributed to its lipophilic properties. The lipophilic opioids rapidly traverse the dura mater, where they are sequestered in the epidural fat and enter the systemic circulation; they also rapidly penetrate the spinal cord where they binds opioid receptors within the white matter as well as dorsal horn receptors and eventually enter the systemic circulation as they are cleared from the spinal cord. It may also exert a supraspinal action by intrathecal cephalic spread $^{10}$.

The duration of sensory block (effective analgesia) was significantly prolonged in group $F(268.6 \pm 55.4)$ compared to group B (182.8 \pm 43.87$)$. The result was similar to study done by various authors ${ }^{1,6-9}$. In our study the duration of analgesia was longer than study done by Safdari $\mathrm{H}$ et al., ${ }^{6}$ that may be due to larger volume of local anesthetic used in our study. Similarly, duration of motor block was also significantly prolonged in group F $(235.03 \pm 51.97)$ compared to group B $(149.47 \pm 38.75)$. The finding is similar to finding of various authors ${ }^{6,7}$. But the results are in contrast to study done by Biswas BN et al. ${ }^{8}$ and Gauchan $S$ et al. ${ }^{11}$ where they have found no significant difference in duration of motor blockade. The prolongation of duration of sensory and motor blockade are as expected because opioids have synergistic effect with local anesthetics ${ }^{12}$.

Side effects such as nausea, vomiting and pruritus were observed. The mechanism for intrathecal opioid-induced nausea and vomiting is thought to be a result of cephalad migration of the opioid in CSF to opioid receptors in the area postrema and chemotactic trigger zone in the medulla ${ }^{13}$. In our study nausea and vomiting occurred in two patients in group $\mathrm{F}$ and three patients in group B and it was statistically insignificant. The findings were similar to studies done by Shende D et al., ${ }^{9}$ Gauchan S et al. ${ }^{11}$ and Chavan $\mathrm{G}$ et al ${ }^{14}$. Some authors have also mentioned decreased incidence of nausea and vomiting with use of intrathecal fentanyl $\left.\right|^{1,8,15,16}$.

The exact mechanism of pruritus is not known. Fan $\mathrm{P}^{17}$ reported that morphine could activate serotonin Type 3 receptors in the dorsal horn of the spinal cord and in the medulla which may be a possible mechanism for the pruritus by intrathecal injection 
of opioids. In our study pruritus was observed in three patients in group $\mathrm{F}$ and none of the patient in group $\mathrm{B}$. The incidence was not so high which was similar to finding of various authors ${ }^{9,11,14}$. Pruritus was mild in all patient and no treatment was requested for it.

In our study $20 \mu \mathrm{g}$ of fentanyl was added intrathecally and no incidence of respiratory depression was found. The reason may be low dose of fentanyl was used so late rostral spread of the drug is less. The finding was similar to finding of various authors ${ }^{8,9,11,14}$. No incidence of any neurotoxicity was observed postoperatively. The hemodynamic variables were comparable between the groups and no other significant adverse effect was observed. The limitation of our study was significant prolongation of duration of motor blockade in fentanyl group which is not desirable for early post-operative recovery.

\section{CONCLUSION}

In conclusion, addition of $20 \mu \mathrm{g}$ fentanyl as adjuvant to bupivacaine offers early onset, better surgical analgesia, prolongs the duration of analgesia without any significant adverse effects. So, it can be recommended that $20 \mu \mathrm{g}$ fentanyl is a safe and promising drug to be used as adjuvant with $0.5 \%$ hyperbaric bupivacaine for spinal anesthesia in infra-umbilical surgeries.

\section{REFERENCES}

1. Bogra J, Arora N, Srivastava P. Synergistic effect of intrathecal fentanyl and bupivacaine in spinal anesthesia for cesarean section. BMC Anesthesiol. 2005;5(1):5.

2. Carr DB, Goudas LC. Acute pain. Lancet. 1999;353(9169):2051-8.

3. Breivik H. Postoperative pain management: why is it difficult to show that it improves outcome? Eur J Anaesthesiol. 1998;15(6):748-51

4. Pert CB, Snyder SH. Opiate receptor: demonstration in nervous tissue. Science. 1973;179(77):1011-4.

5. Rathmell JP, Lair TR, Nauman B. The role of intrathecal drugs in the treatment of acute pain. Anesth Analg. 2005 Nov;101:S30-43.

6. Safdari H, Safari F, Aminnejad R, Mohajerani SA, Farivar F, Mottaghi K. Intrathecal dexmedetomidine and fentanyl as adjuvant to bupivacaine on duration of spinal block in addicted patients. Anesth Pain Med. 2016 February;6(1):e26714.

7. Mahendru VN, Tewari A, Katyal S, Grewal A, Singh R, Katyal R. A comparison of intrathecal dexmedetomidine, clonidine, and fentanyl as adjuvants to hyperbaric bupivacaine for lower limb surgery: A double blind controlled study. J Anaesthesiol Clin Pharmacol. 2013;29(4):496-502.

8. Biswas BN, Rudra A, Bose BK, Nath S, Chakrabarty S, Bhattacharjee S. Intrathecal fentanyl with hyperbaric bupivacaine improves analgesia during cesarean delivery and in early postoperative period. Indian J Anaesth 2002;46(6):469-472.

9. Shende D, Cooper, GM, Bowden MI. The influence of intrathecal fentanyl on the characteristics of subarachnoid block for cesarean section. Anaesthesia 1998;53:706-710.

10. Choi DH, Ahn HJ, Kim MH. Bupivacaine-sparing effect of fentanyl in spinal anesthesia for cesarean delivery. Reg Anesth Pain Med 2000;25:240-5.

11. Gauchan S, Thapa C, Prasai A, Pyakurel K, Joshi I, Tulachan J. Effects of intrathecal fentanyl as an adjunct to hyperbaric bupivacaine in spinal anesthesia for elective caesarean section. Nepal Med Coll J 2013;15(3):156-159.

12. Wang C, Chakrabarati MK, Whitwam JG. Differentiation effect of a Ifentanyl, fentanyl, pethidine and lignocaine administered intrathecally on nociceptive responses evoked by low and high frequency stimulation of somatic nerves. Anesthesiology 1993;79:766-773.

13. Benzon HT, Candido KD, Wong CA. Postoperative Neuraxial Analgesia. In: Wong CA, editor. Spinal and epidural anesthesia. New York: McGraw-Hill; 2006. p. 325.

14. Chavan G, Chavan A, Ghosh A. Effect of intrathecal fentanyl on subarachnoid block with $0.5 \%$ hyperbaric bupivacaine. International J. of Healthcare and Biomedical Research. 2014 July;2(4):67-76.

15. Manullang TR, Viscomi CM, Pace NL. Intrathecal fentanyl is superior to intravenous ondansetron for prevention of perioperative nausea during caesarean delivery with spinal anaesthesia. Anesth Analg. 2000;90:1162-6.

16. Dahlgren G, Hulstrand C, Jakobson J, Norman M, Eriksson EW, Martin H. Intrathecal sufentanil, fentanyl or placebo added to bupivacaine for caesarean section. Anesth Analg. 997;85;128893.

17. Fan P. Nonopioid mechanism of morphine modulation of the activation of 5-hydroxytryptamine type 3 receptors. Mol Pharmacol. 1995;47:491-5. 